\title{
El rey don Pedro en E 1 médioo de su honra de Calderón: entre los (malos) humores y la referencia histórico-legendaria
}

\author{
CÉSAR Avilés ICED O*
}

Resumen:

Este artículo intenta contribuir en la explicación de la configuración del rey don Pedro en E 1 M édioo de su honra de Calderón de la Barca. En una primera instancia, se emprende una valoración de don Pedro revisando acciones y parlamentos en un cotejo constante con lo que la crítica ha expresado. La conclusión de esta valoración es que el personaje difiere de lo que, en general, la tradición siglodeoresca disponía para este tipo de personajes que detentaban la autoridad regia. En una segunda instancia este trabajo explora la caracterización del rey don Pedro a la luz de la teoría de los temperamentos y matiza las reflexiones de ahí generadas echando mano de los datos histórico-legendarios que nutren al personaje. La hipótesis resultante del análisis es que una caracterización de don Pedro confiere congruencia al texto y sirve a los fines que la obra requiere como tragedia, en tanto que al diseñar al rey como una figura de autoridad fallida el microcosmos planteado es propicio para la injusticia y la desgracia; colateralmente la obra pone en tela de juicio un sistema que da lugar a esta anormalidad política y social.

Palabras clave:

Rey don Pedro, Teatro del Siglo de O ro, Calderón, Teoría de los temperamentos.

* Profesor-investigador. Universidad de Sonora. 
Los intentos por caracterizar al rey don Pedro de E 1 médio de su honra (1633-1635), ${ }^{1}$ de Calderón de la Barca, han marchado en diversos sentidos, y pocos coinciden plenamente en sus conclusiones. La trama concatena una serie de sucesos comunes en la dramaturgia del Siglo de Oro: la irrupción repentina de personajes de suprema jerarquía social - un rey y un príncipe- en la vida de un matrimonio de súbditos, los afanes del príncipe para galantear a la esposa honorable y fiel y el accionar dubitativo y titubeante del esposo cuya mirada se distorsiona por los celos. Pero a medida de que avanzan las acciones, hay elementos que se apartan de lo esperable de acuerdo con el uso de aquella dramaturgia: la manera en que el rey intenta controlar personas y acontecimientos en sus cotos de autoridad, el desbordamiento de los hechos que deriva en el asesinato de la mujer, el proceso que exonera de culpas al marido y un nuevo casamiento de éste con otra dama que demandaba la restitución de la palabra de matrimonio recibida de él con anterioridad.

La obra sorprende porque en ella no hay una censura evidente del injusto crimen y porque el accionar de los dos personajes que tutelan a la mujer (el rey en la corte, y el esposo en la casa) se vuelve muy errático en episodios determinantes. D ebe considerarse, por otro lado, que la interpretación se complejiza debido a que en el juego de realidad y ficción propuesto por la obra, el rey y el príncipe tienen sus correspondientes referencias histórico-legendarias: don Pedro - el Cruel o el Justiciero - , y don Enrique - su hermano, quien lo sucedería en el trono de Castilla e inauguraría la dinastía de los Trastámara.

D esde que la obra es leída como un texto cuya principal estrategia discursiva es la ironía y no como portadora de un mensaje expresado literalmente, varias de las interpretaciones ven en ella una crítica al código de honor, pues éste es el elemento determinante del espacio social que rige la conducta de don Gutierre, el esposo, y

${ }^{1}$ Sobre la cronología de la obra véase "Introducción" de D. W. Cruickshank, aE 1 médico de su honra. Todas las referencias a pasajes específicos sobre la obra corresponden a la edición que este estudioso preparó para Castalia. 
que culmina con la consumación del asesinato de Mencía, su mujer (Parker, Wardropper, Amezcua). Cada una de esas interpretaciones ha significado un avance en el acercamiento analítico de la obra pero algunas preguntas que se desprenden de su lectura continúan sin respuesta.

Las bases para una posible explicación de las peculiaridades de la tragedia calderoniana podían encontrase en la preceptiva vigente en ese periodo. A lo largo de la Epístola $\mathrm{V}$ de la Filosofía A ntigua Poética, Alonso López Pinciano refiere las condiciones que deben cumplir las tragedias; parte de la tesis es resumida por Hugo, uno de los coloquiantes de los que se sirve el autor para dictar la norma: "Y así, soy de parecer que el poeta sea en la invención nuevo y raro, en la historia admirable y en la fábula prodigioso y espantoso; porque la cosa nueva deleita y la admirable más" (202). Otras preceptivas más cercanas cronológicamente al Médio...., como $\mathrm{E} l$ arte nuevo de haœer comedias y las Tablas poéticas de Francisco Cascales no difieren mucho de lo que la normativa clasicista señala tan comedidamente. Pero los dictados de dicha norma son demasiado generales; entonces se requiere acercarse a la obra hurgando en sus especificidades.

En estas notas intento un acercamiento que contribuya a explicar la lógica interna de esta tragedia desde la exploración del papel del rey don Pedro, tomando en cuenta dos aspectos íntimamente vinculados en la configuración del personaje: sus acciones y las repercusiones que éstas tienen hacia los demás personajes, y las posibles razones de orden psicológico para tales acciones.

\section{Don Pedro rey y don Pedro hombre}

Visto como una entidad social y psicológica, el rey don Pedro desempeña en la obra un doble papel: como máxima autoridad pública y como persona; ${ }^{2}$ por otra parte, desde la valoración ética, este mis-

${ }^{2} \mathrm{Al}$ analizar la figura del rey en las obras de Lope de Vega, Richard Young (114) hace una observación que quizá no se pueda generalizar en términos absolutos, pero 
mo personaje registra una fluctuación entre un ser y un deber ser, fluctuación que incide en el doble papel mencionado. ${ }^{3}$ Dicho de otra manera, vemos a don Pedro en una oscilación continua entre dos polos: en el cumplimiento de las demandas de su individualidad y de su investidura y en un accionar irregular y atípico que en ocasiones se torna un mentis de tal cumplimiento. Luego, estamos ante lo que $\mathrm{O}$ tis Green (236-37) considera una visión dual de la figura monárquica, ya no tanto en sus funciones de rey y de hombre, sino en una ambivalencia ética que afecta a ambas.

En cuanto al aspecto social de la obra, don Pedro se nos presenta en la cúspide de la pirámide jerárquica, como corresponde a su condición de monarca. Las salutaciones y las comparaciones que los súbditos hacen de su persona evidencian reiteradamente que éstos le reconocen una supremacía indiscutible. Su espacio son las alturas de torres y palacios, desde las que irradia su poder casi sobrenatural, ${ }^{4}$ con lo cual el drama es semejante en este punto a la mayoría de los de la época.

En oposición a lo anterior se encuentra otra dimensión más terrena del personaje, donde su figura es vulnerada de varias maneras: a) en los hechos, por el infante don Enrique, al herirlo accidentalmente; b) en la opinión de dos personajes: don Arias, quien de forma explícita pone en tela de juicio su comportamiento, y Coquín, que entre burlas y veras lo satiriza, y c) por sus acciones, ya que

la considero pertinente para nuestro caso: "fundamentalmente el monarca se caracteriza por su doble personalidad. De un lado está el rey con sus rasgos puramente humanos y sujeto, como cualquier otro hombre, a flaquezas y defectos humanos; $\mathrm{y}$ del otro se encuentra el gobernante, en quien se encarnan los atributos de la institución creada para la regencia de la sociedad, y que llega a erigirse en representante de la sociedad misma". En este mismo sentido se inscribe el estudio de Frances Exum sobre las metamorfosis del rey don Pedro en las siete obras donde Lope lo toma como personaje.

${ }^{3}$ Con la expresión deber ser no sólo me refiero a su conducta, sino también a las expectativas y conceptualizaciones que se tienen sobre la figura regia, y que se dejan ver en los parlamentos de los otros personajes, incluso en los del mismo don Pedro.

${ }^{4}$ En este punto, nos afiliamos a las reflexiones de José Amezcua, quien prueba de forma convincente el lugar de supremacía del rey. 
éstas dejan lugar a ciertas ambigüedades. Creo que el primer inciso no requiere de explicaciones pues, para la época, el simple hecho de que el príncipe haya sacado un arma en presencia del rey significa una violación de las reglas elementales de respeto a la autoridad. Los otros incisos sí merecen una atención más cuidadosa; tanto es así que los hechos referidos en ellos han despertado la polémica y la divergencia de opiniones.

\section{Don Pedro en la perspectiva de los otros, de sí mismo y en sus acciones}

La primera aparición del rey, en la escena de apertura de la obra (I, vv. 5-35), puede ser interpretada en dos direcciones que se contraponen: por un lado se puede tachar de cruel a don Pedro por abandonar a su hermano en lo que parece un trance de muerte; pero por otro lado este evento puede contribuir a realzar su calidad de gran monarca, ya que ni por un contratiempo familiar de esa magnitud deja de cumplir con sus obligaciones de mandatario, lo que se refuerza si se toma en cuenta la instancia desde donde se enuncia el juicio que intenta descalificarlo (quien lo cuestiona es don Arias, privado del Infante; por tanto su objetividad es dudosa) ${ }^{5}$. El episodio es muy importante por ser el que nos presenta a los dos personajes de autoridad, y sólo puede valorarse a la luz de otros acontecimientos de la trama. ${ }^{6}$

En la escena de los pretendientes el rey luce generoso en sus obsequios [I, vv. 578-93], pero no puede obviarse que en sus parlamentos se trasluce una concepción de que el respeto a su autoridad

${ }^{5}$ D e hecho, estas dos maneras para interpretar el accionar del monarca en esa escena corresponden a las que han asumido la gran mayoría de críticos que se han ocupado del texto.

${ }^{6} \mathrm{D}$ e acuerdo con las convenciones del teatro y la literatura de la época, la caída que sufre don Enrique en esa primera escena está cargada de un simbolismo entendido por los espectadores como una anticipación de que el personaje está degradado (en este caso moralmente). 
se debe traducir en un temor hacia su persona. Cualidad y defecto se unen en un mismo hecho; sin embargo, el defecto termina anulando la cualidad porque el temor que el rey inspira es una de las causas primarias de malentendidos y silencios, y éstos a su vez provocan confusiones por las cuales se culpa a doña Mencía. Si en la escena inicial el rey no tenía una responsabilidad directa que pudiera justificar la opinión de don Arias, en ésta sin duda sí la tiene, lo cual ayuda a explicar la opinión negativa que se vierte sobre él: lo que el rey considera una virtud (la gravedad) para los otros es una falla pues, según éstos, su rigor raya en crueldad.

Más adelante tenemos una pista de la concepción que don Pedro tiene de sí. Al dirigirse a Leonor se autodefine como "un Atlante en quien descansa/ todo el peso de le ley" [vv. 675-76]. La perspectiva de otros personajes no coincide con la suya; por ejemplo, a lo largo de la obra Coquín emite opiniones que se oponen a la de don Pedro. Con el fin de ubicar la instancia discursiva desde la que el gracioso se mueve, es conveniente explorar algunas interpretaciones también polémicas que ha generado este personaje. Irving Watson descalifica su voz por considerar que en él se impone su papel de bufón, y anota que éste como gracioso debe ser objeto de burlas y castigos; por lo mismo sostiene que en todo lo que dice merece descrédito (332-38). Este crítico se vale de dos argumentos para sostener sus tesis: en primer lugar explora el estatuto histórico de esta clase de personajes, lo que lo lleva a menospreciar el papel que éstos desempeñan en las comedias; en segundo lugar, equipara a este gracioso con Permín (otro personaje de condición similar que aparece en L a prudencia en la mujer de Tirso de Molina) y establece una comparación entre las relaciones que ambos tienen con otros personajes en sus respectivos textos. Ante lo primero, puede responderse que el desempeño de Coquín no es una calca de un bufón auténtico, lo que repercute de forma importante en la valoración que de él se haga; ante lo segundo, un contraargumento válido es que este gracioso está trazado con una intención distinta de la mera distensión dramática (que es el caso de Permín), pues la "discreción" que lo colorea lo hace una voz autorizada en su apreciación de los hechos, incluso Coquín es el portador de la vox populi y 
en escena declama parlamentos en significativos apartes, y con ello ejerce en cierta medida una función metateatral (Amezcua 191 y Angel M. G arcía G ómez 1033). En respaldo a estas ideas creo oportuno recordar que Coquín, en el "cuento que remata en epigrama" del capón, alude metafóricamente al núcleo de la trama, lo cual lo conecta directamente con los virtuales receptores. Cito aquí los versos que refieren ese asunto:
Yo vi ayer
de la cama levantarse
un capón con bigotera.
¿No te ríes de pensarle
curándose sobre sano
con tan vagamundo parche? (II, 1463-1468)

Mediante el paralelismo sugerido entre el capón y don Gutierre, ¿no se está exponiendo de forma burlesca el caso de don Gutierre que (médico de su honra) piensa que al mandar sangrar a doña Mencía se cura en salud, pensando que con ello lava (cura) su honor, siendo ella totalmente inocente, y por lo tanto su honor está muy sano? Es decir, ¿de qué se quería curar don G utierre si no había enfermedad que atacar?: ipara qué se pone bigotera un lampiño (lampiño por estar castrado)?

Sobre la base de estas consideraciones puede aventurarse que este personaje rebasa el convencional papel humorístico, al mostrar matices que si no lo igualan como personaje a otros del drama en estudio, por lo menos hacen que sus observaciones ocasionalmente cobren mayor peso que las de un simple "hombre de burlas". . Algo similar a lo que ocurre con otros graciosos del drama del Siglo de Oro.

${ }^{7}$ Para J. Amezcua, Coquín tiene una función más extensa como observador crítico del mundo social de la obra: "Coquín integra la oposición a las instituciones dispersa en la obra: las críticas irreverentes contra el rey en boca de don Arias, las inculpaciones que don $\mathrm{G}$ utierre expresa a la crueldad de una ley inflexible, las censuras de las mujeres a los atropellos de los poderosos [...], la oposición, en fin, a los extremos de la enajenación social" (191). 
Coquín expresa repetidamente su certeza sobre la severidad del rey, de ahí su miedo de estar en su presencia y la desconfianza que él le provoca. Impulsado por ese sentimiento, este gracioso aconseja a don Gutierre no regresar a la torre donde se encontraba prisionero y de la cual, con permiso del alcaide, se ha ausentado sólo por una noche (II, vv. 1270-1276). Su pánico lo lleva a afirmar que él será quien el rey quiere que sea, lo cual puede resultar irrelevante dada su condición social y bufonesca, pero ese temor de los súbditos cobra mayor valor cuando don Gutierre expresa casi el mismo sentir ("que menos importa mucho/ que yo deje aquí de ser/ quien soy, que veros airado", I, vv. 900-904). Los parlamentos de este singular gracioso no están exentos de la ironía que permea la obra al catalogar al rey como "un prodigio/ de todos los animales" (II, vv. 1507-1508), porque como ellos no es capaz de reír. A pesar de que en este punto el personaje está más del lado de la distensión que de la "seriedad", su broma no puede pasar desapercibida en su intención crítica.

En el nivel de las acciones don Pedro resulta más contradictorio que en el de los diálogos; es ahí donde el personaje se desmorona en su 'deber ser'. Ya hemos visto que él se concibe como un baluarte de la justicia; debido a esto, ante las demandas que doña Leonor y don Gutierre le presentan, no quiere tomar una determinación hasta no escuchar a las dos partes involucradas, lo cual es plausible; sin embargo, en el mismo momento su conducta se torna errática. En el primero de los casos - con Leonor- su intervención afecta poco en la trama; no así en el segundo - con don Gutierre- , en el que la forma precipitada que lo lleva a adelantar juicios en sus indagaciones acelera el conflicto y deriva en la consumación de la tragedia, luego de que en medio de la confusión el marido celoso termina por dar por ciertas sus equivocadas conjeturas. El casamiento final entre doña Leonor y don Gutierre está sujeto a circunstancias similares; de nuevo parece un acto motivado por la prisa por restaurar el orden; por eso el matrimonio resulta tan forzado. Finalmente, fuere cual fuere la condición esencial del rey, como ocurre a menudo en gran cantidad de dramas del periodo, el rey 
realiza su función de juez. Como señala Lauer: "La personalidad severa o escandalosa del monarca no le quita su potestas" (117).

Las acciones de don Pedro que más nos lo exhiben en el trance de la indefinición entre lo que debe ser y lo que es, son sus valentonadas callejeras en sus paseos nocturnos (II, vv. 1405-1440). Ahí es donde se muestra su faceta de monarca justo, a la par que de justiciero. ${ }^{8}$ D on Diego, que en esta escena funciona como su interlocutor y, casi como su álter ego, aprueba la actitud vigilante de su monarca, pues en tal actitud cumple con lo que de él se puede esperar: que sea "un Argos de su reino, vigilante"; pero inmediatamente después reprueba con un significativo 'Mal hizo su majestad', al escuchar de él que ha enfrentado y vencido a una tropa de "valientes".

Por lo expuesto hasta aquí, en lo concerniente al nivel de las relaciones entre los personajes, podemos concluir que hay un desajuste entre lo que el rey es y lo que debe ser, de acuerdo con las expectativas generadas por el preconstruido cultural vigente en la época y actualizado en la obra por varios personajes y por las parlamentos del rey mismo. Este desajuste se traduce en la degradación del la figura de autoridad y lo que debía representar; así es percibido en la semiótica interna de la obra, la que implica las valoraciones y reacciones de los otros personajes; lo mismo sucede hacia el nivel semiótico externo, el de la recepción del público, porque la figura de Coquín - en su papel metateatral- ofrece al auditorio

${ }^{8}$ Hago la distinción entre ambos términos, en atención a que justiciero tiene todavía en el siglo XVII una derivación semántica que actualmente se ha diluido. Bajo la entrada Justiciero Covarruvias registra la siguiente acepción: "el que guarda el rigor de la justicia; este tal ha de picar un poquito en cruel, porque summum ius, summa iniuria. Ajusticiar, executar en alguno la pena de muerte, al que llaman ajusticiado" (725). El siguiente fragmento de un texto de Menéndez Pelayo ilustra también una de las connotaciones que tenía la palabra: "Ese acto de barbarie [el fratricidio] que hoy nos espeluzna, era punto por punto análogo a los de Alfonso XI, cuando a los quince años descabezó en Toro al señor de Vizcaya; cuando hizo matar en otra emboscada al conde de Trastámara, Alvar Núñez, y arrojar al fuego su cadáver; cuando en una cacería hizo alancear por dos pajes suyos de lajineta aD. Juan Alfonso de Haro, señor de los Cameros. Estos abreviados procedimientos recibían en el siglo XIV el nombre de justicias. (43- 44). 
vías de interpretación de lo que es el personaje, así como de sus acciones. En una instancia inmediata las fallas del rey pueden atribuirse a que a veces privilegia su investidura social y política sobre su condición de hombre individual, mas en otras ocasiones no es ésta la razón de su proceder. D ramatúrgicamente la tragedia demanda cierta "desmesura (hybris)" del personaje para que haya congruencia en el devenir de los hechos que en ella se tratan.

\section{Don Pedro y la teonía de los temperamentos}

D esde la década de los setentas del siglo veinte, en la crítica de la literatura áurea se fue imponiendo una postura que daba mayor importancia a la configuración de los personajes ya no como "tipos", 0 "ideas representables" (tan desarrollada por la crítica inglesa, encabezada por el A. A. Parker de los "Cinco principios estructurantes del D rama de los Siglos de Oro"), sino como personajes con complejidad humana y profundidad psicológica(Frenk). Como una vertiente de este modo de acercarse al fenómeno, emergió una línea de estudios que intentaba explicar la configuración de personajes a partir de los modelos establecidos por la teoría clásica de los temperamentos que a fines de la Edad Media y durante el siglo XVI cobró gran vigor. Esta teoría se había revitalizado con las movilización de los aportes de los pensadores y médicos grecolatinos (Aristóteles, Hipócrates, Galeno) y las constantes revisiones, enmiendas e reinterpretaciones que rindieron traductores, médicos y filólogos de la baja Edad Media y del Renacimiento (Bleznick 2), al punto de que "la melancolía se ubica como uno de los ejes fundamentales de la cultura renacentista" (Bartra 53-54). A la luz de esta teoría se proponen posibles explicaciones a conductas de personajes difíciles de comprender. Las miradas caen sobre don Quijote y otras creaturas cervantinas como los personajes melancólicos más atractivos del periodo. ${ }^{9}$

${ }^{9}$ Volviendo la mirada a textos limítrofes entre la Edad Mediay el Renacimiento, se observa que en la mente de los escritores la teoría de los humores tenía su lugar. 
Así, los comportamientos "extraños" de los hombres contemplados por esta caracterología, actualizada por textos tan influyentes como el E xamen de ingenios para las ciencias de Juan Huarte de San Juan, se verían representados por algunos de los escritores de la época; la literatura y el teatro vendrían a ser la puesta en letra y en escena de patologías reconocidas que provocaban situaciones problemáticas. ${ }^{10}$ Según lo que se lee en el E xamen... las conductas de todos los hombres son erráticas; entonces todos están enfermos de una u otra manera:

El hombre es todo enfermedad desde que nace [dice Huarte utilizando las palabras con las que supuestamente D emócrito Abderita se dirigió a Hipócrates]. Mientras se cría, llora porque le valgan; mientras crece, es rebelde, ignorante, necesitado de preceptor; llegado a la pujanza, es temerario; cuando ya decae, da lástima contando y ponderando su vida... Así hace su camino desde las miserias de la matriz. (52)

También por esta enfermedad universal las relaciones entre los hombres no son más que una obra de teatro, como lo expresa el médico renacentista al continuar su reflexión:

De la cual sentencia se admiró Hipócrates y, pareciéndole muy verdadera, se dejó conducir y por tal la cantó a su amigo

Como señala Roger Bartra: "En el Corbacho y en L a Celestina vemos el fascinante fenómeno mediante el cual la cultura renacentista - en este caso la literatura- tomó como base 0 , mejor, como textura los estudios médicos sobre la melancolía: el humor negro permitió urdir un tejido sentimental para poner a prueba las emociones eróticas. L a C elestina es evidentemente una mujer que parodia el oficio de médico, y trata la enfermedad de Calisto como hubiera querido Avicena: auspiciando la relación carnal con Melibea; sus conocimientos de farmacología, sus aparatos alquímicos, el uso de hierbas medicinales, sus aparejos para baños y sus habilidades en cirugía podrían ser la envidia de muchos médicos de la época, y podemos suponer que sus recetas no debían ser muy diferentes a las de Pedro Hispano" (141).

${ }^{10}$ Coincidimos con Mauricio de Iriarte en su afirmación de que el libro de Huarte era posiblemente una referencia en la mente de los dramaturgos del Siglo de O ro. 
Damageto. Y tornándolo a visitar - gustando de su sabiduría- dice que le preguntó la razón de su continua risa (viéndole reír y burlar de todos los hombres del mundo); a lo cual le respondió la sentencia que sigue: “¿Acaso no adviertes que todo el mundo está enfermo?... Unos compran perros y otros caballos; quieren mandar sobre muchos y no saben mandar sobre sí; toman mujer y al poco la repudian; aman y luego aborrecen; afanan por tener hijos, y de mayores los echan de casa... ¿Q ué absurdo afán es éste que nada difiere de la demencia?... Se hacen guerras civiles, reñidos con la paz; deponen reyes, los reemplazan; matan hombres; cavan la tierra en busca de oro..." Y así procedió muy a la larga contando los varios apetitos de los hombres y las locuras que hacen y dicen por razón de estar todos enfermos. Y concluyendo le dijo que este mundo no era más que una casa de locos, cuya vida era una comedia graciosa representada para hacer reír a los hombres; y que ésta era la causa de que reía tanto. (52-53)

No sería descabellado, entonces, pensar que algunos escritores del Siglo de Oro, influidos por esta manera de interpretar el mundo, sintieran que al producir sus obras sólo estaban haciendo una trasferencia de la realidad a la palabra. Esto tiene relevancia particular para el presente trabajo porque el autor de la obra que tratamos manifiesta un pensamiento que coincide en más de una ocasión con lo expuesto por Huarte.

Afiliada a la línea crítica referida, y aplicada al M édioo de su honra, se encuentra una sugerente hipótesis de Teresa Soufas, quien sustenta que don Pedro está diseñado sobre el paradigma de un hombre melancólico. A su favor tiene una serie de argumentos que casan apropiadamente con las ideas que se desprenden de los textos que en el periodo tratan el asunto, en especial con lo expuesto en el E xamen... Soufas hace un recuento de las principales características que generalmente se asocian con ese temperamento: la gravedad y el temor, la actitud constante de celo y de sospecha, el insomnio, la preferencia por la oscuridad y la soledad; además, añade Soufas, los melancólicos pueden sufrir alucinaciones, obsesión por la muerte y otras fijaciones irracionales. (59) 
Esta interpretación incluso se podría reforzar apelando a otros autores de la época, como Pedro Ciruelo, Jean Fernel (o Fernelius) y Pedro de Mercado. Ciruelo ofrece la siguiente explicación de los sueños: "si se mueue [...] la melancolia, sueña [el hombre] cosa negras, escuras y cosas tristes y de muertos" (57). Esta sintomatología es aplicable al personaje que nos ocupa, quien en reiteradas ocasiones se muestra como un hombre temeroso de su porvenir y refiere que sus sueños le advierten un inminente peligro de muerte; su comportamiento en la escena donde el príncipe Enrique saca el puñal en su presencia, tiene como telón de fondo esta premonición de don Pedro. Lo mismo puede decirse de los otros dos médicos citados. Fernelius hace una enumeración de conductas y sentimientos que corresponden a la melancolía y que mutatis mutandis cuadran con la imagen que se ofrece del monarca: "La tristeza, el temor frecuente e inmotivado, la soledad, la meditación profunda y grave, el sueño turbulento y perturbado por diversas y terribles pesadillas; todo denuncia que se trata de melancolía..." (Citado por Bartra 48). En este sentido avanza más todavía Pedro de Mercado para quien, en resumen de Bartra, "Los melancólicos están siempre descontentos, recelan de todo, huyen sin que se les persiga; [Mercado] los describe con una expresión popular: 'es un pelear con el duende', para aludir a que ellos solos se juzgan, se preguntan, se responden, se condenan y se absuelven en una intensa lucha interior" (77).

La cita a Mercado igual valdría para explicar la incapacidad del personaje para reír, pues a pesar de todos los esfuerzos que hace Coquín no logra arrancarle al rey una sonrisa y con ello pierde la apuesta entre ellos pactada. Hurgando en el Examen... encontramos que la risa se explica también en términos de los humores. La sangre, "que es un humor benignísimo", provoca la risa y, por el contrario, la melancolía genera la congoja (Huarte 144).

En resumen: según este acercamiento apegado a la caracterología, más que configurar al personaje como cruel o justo, Calderón lo presenta como un hombre enfermo, porque siguiendo las oscilaciones conductuales de nuestro personaje vemos repetidas coincidencias de lo contemplado por Huarte en su tratado referente a las enfermedades. De tal suerte que ese rey casi resulta una ilustración 
de lo anotado en el fragmento del diálogo citado arriba entre Hipócrates y D amageto. La razón sería la destemplanza en los humores corporales y sus efectos en la mente; es decir, en don Pedro hay un exceso de melancolía, con los derivados inherentes: su volubilidad, sus recelos y el modo en que asume su responsabilidad como rector de la vida de sus súbditos.

Sin descalificar el valor de esta propuesta, convendría detenerse en algunos aspectos que matizan una afirmación de tal naturaleza.

El primero es que no se puede desconocer la tradición, una tradición que es más poderosa y efectiva que la Historia en el caso que tratamos. Algunos estudios, con vigencia aún, se han orientado a explicar la construcción del personaje del rey mediante estrategias que movilizan las referencias histórico-legendarias que nutren esta tradición (Loyd King, Dian Fox e I. Benabu). En ellos queda claro que en la C rónica del rey $D$ on Pedro de López de Ayala y en muchos de los romances (Romancero del rey D on Pedro), el tinte con que se colorea al personaje recalca su carácter despiadado y sañudo. Además, hay datos históricos de los que también la tradición echó mano para acentuar el supuesto comportamiento desleal y cruel del monarca: el repudio a doña Blanca de Borbón al día siguiente de los esponsales (que por cierto, apunta la leyenda, derivaría en el encierro de la reina en una torre y concluiría con su asesinato), las constantes guerras fratricidas (que registran la muerte de dos de sus hermanos causada por don Pedro, además de otros desmanes hasta que don Enrique lo mata a él), o la actitud vengativa y legendariamente arbitraria de don Pedro para con quien se le opusiera políticamente.

El segundo está relacionado con las interpretaciones que tiene un hecho tan simple como la risa o la incapacidad de reír, que han servido para cargar las tintas sobre el carácter adusto y feroz del monarca. Una exploración histórica y filológica nos indica que en la Edad Media y el Renacimiento el hombre que no reía no era visto con recelo o prejuicio. A ese tipo de hombre se le aplicaba el adjetivo griego de agelastos, y la percepción sobre ellos no sólo no era negativa sino tan favorable en algunos casos, que incluso Cristo era considerado en esa categoría (García Gómez 1030-1031). 
El tercer aspecto en el que convendría detenerse para valorar hasta qué punto se puede sostener la interpretación de don Pedro como un hombre de proceder errático por su melancolía, nos obliga a pensar en las implicaciones que tenía que un individuo fuera reconocido como afectado por el exceso de alguno de los humores. Hasta donde se aprecia, según el trabajo de Soufas la melancolía que provoca la destemplanza, sólo aporta efectos negativos en don Pedro, sin reconocer las virtudes que de ella podía obtener. Sin embargo, Huarte es muy enfático para asentar que el desequilibrio de los humores no es en sí un gran problema, sino el errar en la actividad adecuada a tal o cual temperamento: "Los hombres templados - se lee en el texto - tienen capacidad para todas las ciencias con cierta mediocridad, sin aventajarse mucho en ellas. Pero los destemplados, para una y no más; a la cual si se dan con certidumbre, y la estudian con diligencia y cuidado, harán maravillas en ella; y si yerran, sabrán muy poquito en las demás" (57). De hecho, se creía que los hombres de letras que han pasado por la historia fueron todos melancólicos y eso había sido factor muy importante para que fueran sobresalientes. Por lo menos se debería tener en cuenta que hay variadas opiniones en cuanto a las calificaciones humorales (incluso en el mismo Huarte). ${ }^{11}$

El cuarto refiere al modo en que se caracteriza a don Pedro como un hombre melancólico. Por lo ya expuesto arriba, hay que recalcar que los argumentos para presentar a don Pedro en tal destemplanza no carecen de sustento; el problema radica en que cualquier afirmación categórica al respecto puede resultar excesiva. Si leemos lo

${ }^{11}$ De esta manera lo indica Bleznic, y también refiere las cualidades positivas que pueden favorecer a los sanguíneos y coléricos citando a uno de los tratadistas políticos:

Furió [se refiere a Fadrique Furió Ceriol, autor de El conojo y consejeros del prínipe] escogió al sanguíneo y al colérico como los mejores consejeros del príncipe. Según sus palabras, las personas de estos temperamentos son "ingeniosos, tienen razonable memoria, saben hacer discursos, tienen claro juicio; son justos, amorosos, afables, leales, benéficos, magníficos, magnánimos i fuertes en su naturaleza; i en el cuerpo sueltos, ágiles, sanos i de buen temple" (4). 
que apunta Fray Luis de León, quien apela a Galeno y Aecio, para definir a un melancólico, vemos que el rey don Pedro no es exactamente lo que ahí se declara:

Sabido es lo que el padre de los médicos dice, "que la melancolía a los que fatiga, los hace tristes y muy temerosos, y de ánimo vil". Y otro médico muy señalado: "Unos, dice, temen a sus más amigos; otros se espantan de cualquier hombre que sea; éste no osa salir a la luz; aquél busca lo oscuro y lóbrego; otro lo teme y lo huye; algunos se espantan del vino y del agua y de todo aquello que es líquido; y como la melancolía sea de muchas diferencias, pero en todas es común y general el hacer tristeza y temor; que todos los melancólicos se muestran sañudos y tristes, y no pueden dar de su tristeza razón, y casi todos los mismos temen y se recelan de lo que no merece ser recelado". (Citado por Bartra 120)

En todo caso este diseño del temperamento melancólico es cercano a don Gutierre más que a don Pedro. En un estricto apego a la caracterología, como personaje melancólico el rey sería un incapacitado para realizar acciones temerarias, como la de enfrentar a "valientes" en medio de la noche. Al contrario de ello, de él sería esperable que intentara permanecer bajo el buen refugio del palacio y sus guardas. Es cierto que algunos melancólicos tienen conductas explosivas, un poco al estilo del Cardenio cervantino, pero ésas son entendidas como expresiones de locura temporal que en cuanto se desvanecen dejan al hombre apaciguado y aún más vuelto hacía sí que antes de que ocurriera el ataque (el "accidente", dice el narrador del Q uijote). El comportamiento del rey en esos episodios del drama, hace pensar más bien en un temperamento colérico. En palabras de Huarte, el colérico "según la irascible adora en la hon-ra, en la vanagloria, imperio y mando, y ser de todos superior" (51).

Existe otra divergencia entre la caracterización del personaje y los elementos distintivos del humor melancólico. Retomando a Aristóteles, se señala que "la mayor parte de los melancólicos están 
obsesionados con el sexo" como se asienta en el Problema X X X , 1, del estagirita (citado por Bartra 129), y en la obra el único personaje con conductas que corresponderían a este apunte es don Enrique, que se muestra incontinente en su apetito por doña Mencía; por el contrario, a don Pedro se le ve muy mesurado (por cierto muy a diferencia de otros dramas donde sus devaneos y deseos lujuriosos provocan desorden y pequeños cataclismos, de manera similar a la que aquí lo hace el príncipe).

También hay que señalar que el texto de Huarte se ocupa en un espacio preferencial al padecimiento del melancólico y descuida los padecimientos ocasionados por el exceso de los otros humores. ${ }^{12}$ Esto es muy explicable porque la melancolía se entendía como un padecimiento extendido sobre el que se debía tener especial cuidado y porque en la literatura sobresaliente del siglo XV el asunto ocupó un lugar preeminente por la relación que se tendió entre el padecimiento y el mal de amor. Pero ese descuido que se tiene con los otros temperamentos nos advierte que los juicios sobre las conductas de los personajes y su encasillamiento en tal o cual carácter debe tomarse con reservas.

A la luz de estas reflexiones y de los datos que nos ofrecen los textos de la época, se puede adelantar como una conclusión primera - a reserva de una investigación más acuciosa- que don Pedro cumple un papel que el dramaturgo moviliza a conveniencia de la obra y de acuerdo con lo que demandaba la audiencia. De la misma manera que el don Pedro que tenemos en escena no es el don Pedro histórico, ${ }^{13}$ tampoco tenemos en él el ejemplo vivo de un caso clíni-

${ }^{12}$ Incluso hay diferencias entre Huartey otros médicos que le son contemporáneos, como Andrés de Velásquez, para quien la causa de los males no era el desequilibrio de los humores sino el color excesivamente negruzco del humor melancólico. «Para el doctor Andrés de Velásquez, y siguiendo a G aleno, la enfermedad era debida al "color tenebroso y negro del humor atribilioso" y no a la "destemplanza" de las calidades" como suponían Avicenay Averroes» (Bartra 125).

${ }^{13}$ Como apunta Lauer, el "referente histórico... no es sólo sugerente sino estéticamente eficaz, sobre todo si tomamos en cuenta la función tradicional de esta persona regia en particular" (118). Y como consigna R. Young: "Los monarcas de las comedias son, en su mayoría, sacados de la historia, pero el dramaturgo se fija 
co. La congruencia de la tragedia, en lo que concierne al personaje del rey, es provista por un accionar fluctuante del personaje entre varias patologías que cuadran muy ad hoc con la figura histórica de la cual la mayor parte de los espectadores estaba al tanto por los distintos medios (crónicas, romances, leyendas) y porque el personaje, hay que recordarlo, gozaba de gran popularidad y ya había sido utilizado en al menos diez obras de teatro del Siglo de Oro. ${ }^{14}$

También habría que tener en cuenta que en otras obras en las que el rey don Pedro aparece como personaje, su caracterización es muy variable; en la minoría de ellas se le ve como el más justo de los monarcas, pero en las otras se le presenta arbitrario y prepotente en sus afanes de conseguir lo que desea. Más extrema aún es su desmesura cuando aparece en su faceta de galán obsesionado y lo que desea es obtener los favores de la dama. Lo que importa en el juego dramático expuesto, pues, es que don Pedro, como hombre y como monarca, está afectado en su ser y en su deber ser y con ello también se afecta su buen gobierno, por eso en la obra se convierte en un factor muy importante de la tragedia; como cabeza del mundo que debe regir no funciona positivamente, está demasiado degradado en los hechos pero también lo está desde antes de iniciar la obra por la carga legendaria que lo marca; en consecuencia, su reino está también en un proceso de descomposición. En un ambiente así, es lógico que la justicia y la verdad se releguen y que los personajes inocentes con los cuales el público establecería una relación de simpatía caigan en desgracia, lo cual confiere congruencia y consistencia a la tragedia.

solamente en algunos rasgos de su personalidad al trasladarlos en escena. Dicho fenómeno es especialmente evidente en el caso de Pedro I de Castilla" (29).

${ }^{14}$ Hasta ahora la historia literaria reconoce dieciocho obras de teatro del Siglo de O ro que toman al rey don Pedro como personaje (Lomba y Pedraja). El personaje daría para más en diversos ámbitos culturales: su persona fue retomada por otros autores del siglo XIX, como el D uque de Rivas ( R omances histórioss) o Prosper Merimée (L e Roi don Pedro) y D onizzeti (en la ópera D oña M aría de Padilla), y en el siglo XX al menos por García Lorca (P oema del cantejondo). 


\section{Bibliografía}

Amezcua, José. L ectura ideológica de Calderón. E l médioo de su honra. México: Universidad Autónoma Metropolitana/ Universidad Nacional Autónoma de México, 1991.

Bartra, Roger. E 1 Siglo de 0 ro de la melancolía. Tex tos españoles y novohispanos sobre las enfermedades del alma. México: Universidad Iberoamericana, 1998.

Benabu, I. "Further thoughts on King Pedro's predicament at the end of Calderón's El médio de su honra." Bulletin of H ispanic Studies 59 (1982): 26-32.

Bleznick, D onald W. "La teoría de los humores en los tratados políticos del Siglo de Oro." H ispanófila 5 (1959): 1-9.

Calderón de la Barca, Pedro. El médico de su honra. Ed. D. W. Cruickshank. Madrid: Castalia, 1981.

Ciruelo, Pedro. Tratado de las supersticiones. Puebla: Universidad Autónoma de Puebla, 1986 [Edición facsimilar del Tratado en el qual se reprueban todas las supersticiones y hechizerías: muy vtil y necesario a todos los buenos christianos zelosos de saluacion. Barcelona: Ed. Sebastián de Cormellas, 1528].

D unn, Peter N. "Honour and the Christian Background in Calderón." Critical E ssays on the Theatre of Calderón. Ed. Bruce Wardropper. New York: New York University Press, 1965. 24-60.

Exum, Frances. The M etamorphosis of L ope de V ega's King Pedro (The Treatment of Pedro I de Castilla in the D rama of $\mathrm{L}$ opedeV ega). Madrid: Plaza Mayor, 1974.

López Pinciano, Alonso. Filosofía A ntigua Poética. Ed. Pedro Muñoz Peña. Valladolid: Imprenta y Librería Nacional y Extranjera de Hijos de Rodríguez, Libreros de la Universidad y del Instituto, 1894.

Fox, Dian. "E 1 M édioo de su H onra, Political Considerations." H ispania 65 (1982): 28-38.

Frenk, Margit. "El personaje singular: un aspecto del teatro del Siglo de Oro." N ueva Revista de Filología H ispánica 26 (1977): 480-98. García Gómez, Ángel M. "E 1 médico de su honra: perfil y función de Coquín." Calderón. A cas del Congreso Internacional sobre Calderón y 
el Teatro E spañol del Siglo de 0 ro, t.2. Ed. Luciano G arcía Lorenzo. Madrid: C.S.I.C., 1983.

Green, Otis. "La dignidad real en la literatura del Siglo de Oro: notículas de un estudioso." Revista de filología española 48 (1965): 231-50.

Huarte de San Juan, Juan. E x amen de ingenios para las ciencias. Argentina: Espasa-Calpe, 1948.

Iriarte, M. de. El doctor H uarte de San Juan y su examen de ingenios; contribución a la historia de la psicología diferencial. Madrid: C.S.I.C., 1948.

King, Loyd. "The role of King Pedro in Calderón's El médico de su honra." Bulletin of the Comediantes 23 (1971): 44-49.

Lomba y Pedraja, J. "El rey don Pedro en el teatro." H omenaje a M enéndez y Pelayo. Ed. Juan Valera. Madrid: Victoriano Suárez, 1989. 257-339.

Lauer, Robert. "Las Mencías: tres problemas y un personaje." El escritor y la crítica. E studios sobre teatro español y novoshispano de los Siglos de $\mathrm{O}$ ro. H omenaje a M arc V itse. Ed. Y sla Campbell. México: Universidad Autónoma de Ciudad Juárez, 1997. 115-23.

Menéndez Pelayo, Marcelino. A ntología de poetas líricos castellanos. 0 bras completas, t. 7. (Parte II: Tratado de los romances viejos, II) y t.8, (Parte II: Los romances viejos, III). Ed. Enrique Sánchez Reyes. Madrid: C.S.I.C., 1954.

Parker, A. A. "Hacia una definición de la tragedia calderoniana." Calderón y la crítica, Eds. I. Manuel Duran y Roberto González Echeverría. Madrid: Gredos, 1976: 359-87.

. The A pproach to the Spanish D rama of the G olden A ge. London: The Hispanic and Luso-Brazilian councils, 1957.

Romancero del Rey don Pedro (1368-1800). Ed. Antonio Pérez Gómez.

Valencia: '...la fonte que mana y corre... ', 1954.

Soufas, Teresa. "Beyond justice and cruelty: Calderón's King Pedro." Journal of H ispanic Philology 6 (1981): 57-65.

Velásquez, Andrés. Libro de la melanoolía, en el cual se trata de la naturaleza de esta enfermedad, así llamada melanoolía, y de su causa y síntomas. Y si el rústio puede hablar latín, o filosofar, estando frenétio 0 maniaco, sin primero lo haber aprendido. En Roger Bartra. El siglo 
de oro de la melanolía. Tex tos españoles y novo-hispanos sobre las enfermedades del alma. México: Universidad Iberoamericana, 1998: 255-373. [Edición de Sevilla: Hernando D íaz/ Alonso de Mata, 1585]

Watson, Irving. "Peter the Cruel or Peter the Just? A Repraisal of the Role Played by King Peter in Calderon's E 1 medioo de su honra." Romanistisches Jahrbuch 14 (1964): 322-45.

Wilson, Edward M. y D uncan Moir. Historia de la literatura española, III. Siglo de Oro: teatro. Barcelona: Ariel, 1974.

Young, Richard. L a figura del rey y la institución real en la comedia lopesca. Madrid: Porrúa Turanzas, 1979. 